\title{
Aberrant Immunoglobulin Synthesis in Light Chain Amyloidosis \\ Free Light Chain and Light Chain Fragment Production \\ by Human Bone Marrow Cells in Short-term Tissue Culture
}

\author{
Joel Buxbaum \\ with the technical assistance of Donald Hauser \\ Departments of Medicine and Pathology, New York University Medical Center Research Service, \\ New York Veterans Administration Medical Center, New York 10010
}

\begin{abstract}
Bone marrow cells obtained from 14 patients with light chain amyloid (AL) deposition were examined by biosynthetic labeling techniques. These analyses identified free monoclonal light chain (L-chain) synthesis even in those patients whose serum or urine contained no $M$ protein or free $L$-chains or only an intact $M$ protein. The experiments also identified a subset of patients whose plasma cells synthesized polypeptides bearing constant region antigenic determinants that migrated more rapidly than intact L-chains on polyacrylamide gels. Since most AL fibrils contain L-chain fragments rather than intact L-chains, these studies suggested that the genesis of the fibril components may reflect aberrant synthesis, proteolytic processing, or both. We also noted that in some individuals the pattern of Ig synthesis normalized after several courses of cytotoxic therapy. Thus, we could use bone marrow Ig synthesis as a sensitive biochemical parameter for monitoring therapy. Finally, the presence of aberrant synthetic products in these clones raised questions about their origin with respect to the normal processes of transcription, translation, and posttranslational modification in Ig-producing cells.
\end{abstract}

\section{Introduction}

It has been known for several years that the major fibrillar protein found deposited in the tissues of individuals with primary amyloidosis and the amyloidosis associated with multiple myeloma, i.e., light chain (AL) ${ }^{1}$ amyloidosis, is related to a monoclonal light chain (L-chain) (1). In most patients a monoclonal M protein or free L-chain has been found in the serum or urine (2). In several cases the amino acid sequences of the fibril and the monoclonal urine or serum protein have been determined and found to be identical $(3,4)$. Many fibril proteins have been studied in detail and reported (3-10). In only 5 of 17 cases have the deposits contained intact L-chains. In two, L-chain monomers were the only component of the extracted fibrils. In the majority, the deposits have contained primarily fragments, all of which have normal $\mathrm{L}$-chain variable ( $\mathrm{V}$ region) amino-termini. Three

A portion of this work was presented at the Fourth International Conference on Amyloidosis, Harriman, New York, November 1984. 1986

Received for publication 5 August 1985 and in revised form 9 May

1. Abbreviations used in this paper: $\mathrm{AL}$, amyloid light chain, $\mathrm{H}$-chain, heavy chain; L-chain, light chain; SH, sulfhydryl; V, variable.

The Journal of Clinical Investigation, Inc.

Volume 78, September 1986, 798-806 of these also contained intact L-chains. In a few cases the reduced peptides are larger than normal L-chains. The biogenesis of the short fragments could represent proteolysis, aberrant synthesis, or a combination of both. The longer molecules may represent distorted synthesis or polymerization via nondisulfide mechanisms, taking place either in vivo or during fibril preparation.

These observations pose the following question. Is deposition a function of the synthesis of intact or aberrant proteins that are susceptible to tissue deposition per se, or does specific proteolysis of any L-chain render it insoluble and liable to pathologic tissue deposition? If synthesis of abnormal Ig subunits is critical, then the presence of the deposition disease will identify individuals in whom detailed analysis of synthesis may be useful in further elucidating the mechanisms regulating the production of $\mathrm{Ig}$ polypeptides.

The present studies were designed to examine Ig biosynthesis in patients with AL disease to determine if the deposited proteins could be primary synthetic fragments. We have also attempted to use the same analytic techniques as clinical tools in the evaluation of patients with this disorder, particularly those patients whose serum and urine do not contain free monoclonal L-chains.

\section{Methods}

All patients had biopsy-proven amyloidosis. Sera from all patients were examined by cellulose acetate electrophoresis and immunoelectrophoresis with a variety of monospecific, commercially available antisera with wellcharacterized heavy or L-chain specificity (11). Urines were concentrated up to 400 -fold if no evidence of a monoclonal protein was noted at a 25-fold concentration. Concentration was carried out by either Sephadex absorption or the use of minicon membranes (Amicon Corp, Danvers, MA) (12).

Biosynthetic studies were performed using bone marrow cells obtained at the time of diagnostic aspiration and biopsy. Marrow was aspirated into a heparinized syringe and transferred to a sterile polypropylene tube containing $25 \mathrm{ml}$ of Eagle's minimal essential medium lacking valine, leucine, and methionine, but containing $5-10 \mathrm{U} / \mathrm{ml}$ of heparin without preservatives [( -$)$ medium]. The cells were centrifuged at room temperature and the buffy coat removed. The buffy coat was washed twice more in (-) medium, resuspended in $5 \mathrm{ml}$, and the live nucleated cells enumerated after erythrocin B staining (13). The cell concentration was adjusted with (-) medium to between 3 and $5 \times 10^{6}$ cells $/ \mathrm{ml} .100 \mu \mathrm{Ci}$ each of $\left[{ }^{3} \mathrm{H}\right]$ valine and leucine and $100 \mu \mathrm{Ci}$ of $\left[{ }^{35} \mathrm{~S}\right]$ methionine were neutralized with isotonic-buffered saline and added to each milliliter of cell suspension at time 0 . The number and spacing of the time points were determined by the number of cells available. The percentage of plasma cells in the marrow was determined by examination of the smear by the attending hematologist. In some cases, where therapy was instituted, repeat marrow examinations were performed at intervals deemed appropriate by the patients' attending physicians.

Analyses of the synthesized and secreted material were carried out after separation of the cells and supernatant medium. At each time point 
the sample was made $0.1 \mathrm{M}$ with respect to iodoacetate in order to block free sulfhydryl (SH) groups and prevent polymerization by disulfide interchange, and chilled. The cells were centrifuged in the cold and the supernatant removed and saved for analysis as secreted material. The cell pellet was suspended in $9 \mathrm{ml}$ ice-cold distilled water for $1 \mathrm{~min}$ in order to lyse residual red cells, then brought to isotonicity by the addition of $1 \mathrm{ml}$ of $10 \times$ buffered saline. The cells were centrifuged in the cold (10 min). The supernatant was removed and the pellet washed again with cold medium. The final cell pellet was suspended in $1 \mathrm{ml}$ hypotonic buffer per $5 \times 10^{6}$ cells and 0.1 vol $5 \%$ Nonidet P-40 (NP-40) added (14). The tube containing the cells was placed in an ice bucket for 30 min then spun at $100,000 \mathrm{~g}$ in an ultracentrifuge (L265B; Beckman Instruments, Inc., Fullerton, CA) using a 50 rotor. The resultant supernatant fluid was treated as cytoplasm. Trichloroacetic acid precipitation of 10- $\mu$ l portions of cytoplasm and secretions were performed to establish the linearity of incorporation of radioactive precursors into total cell protein and secretions and to determine the relative amount of protein synthetic activity by the marrow cell population (15).

Immunologic precipitations of radioactive cytoplasm and secretions were carried out with a variety of commercially available polyclonal and monoclonal antisera specific for particular Ig chains. Some antisera were prepared in our own laboratory. Each of the antisera was titrated against a 1/50 dilution of a normal standard reference serum, which was then used as a carrier in the experimental precipitations. A calculated twofold excess of antibody to carrier was utilized in all precipitations. When monoclonal antibodies were used, all samples were precleared with staphylococcal protein A beads before the addition of the monoclonal antibody and a second portion of protein A-containing beads adequate to bind the added antibody (16).

Precipitates were washed with $0.5 \mathrm{M} \mathrm{NaCl}$ and $0.05 \% \mathrm{NP}-40$ three times, then vigorously dispersed in $50 \mu \mathrm{l} 2 \%$ sodium dodecyl sulfate (SDS) and $0.5 \% \mathrm{NP}-40$, and then placed in a boiling water bath for 1 min. Staphylococcal protein A-bound antigens were released by boiling the beads in 2\% SDS and 0.5\% NP-40 and separating the solubilized bound material from the beads by centrifugation. The specifically precipitated radioactivity in the precipitates was determined by liquid scintillation counting. The amount of immunologically precipitated radioactive protein determined how much of each precipitate would be reduced and alkylated (10 mM dithiothreitol and $0.1 \mathrm{M}$ iodoacetamide) before gel analysis.

Unreduced samples were generally electrophoresed on 7.5-10\% polyacrylamide gels containing $0.1 \%$ SDS. Reduced samples were run on $17.5 \%$ gels. We noted that in some cases the reduced and alkylated L-chain monomers migrated more slowly than naturally occurring unreduced L-chains. Gels were processed using either ENHANCE or Enlighten (New England Nuclear, Boston, MA), dried on filter paper in a gel-drying apparatus, and exposed for autoradiography (17).

Known marker proteins were electrophoresed on each gel. A representative analysis of the proteins synthesized by an individual with polyclonal hyperglobulinemia is shown in Fig. 1.

The major molecule synthesized was IgG, which was precipitable with both anti-kappa and anti-lambda sera (Fig. $1 \mathrm{~A}$ ). IgM was also precipitable with both antisera and found at the top of the gel (Fig. $1 \mathrm{~B}$ ). Fig. 1, lane 1 shows that the anti-kappa serum also precipitated molecules that migrated as L-chain monomer and dimer (Fig. $1 C$ and $D$ ). A faint band (Fig. $1 E$ ) corresponding to the position of lambda dimer could also be discerned (Fig. 1, lane 3). Reduction and alkylation of both the kappa and lambda precipitates released heavy chains (H-chains) (Fig. 1, lanes 2 and 4 ) and the respective L-chains. No fragments bearing heavy or L-chain antigenic determinants were noted.

\section{Results}

11 of the 14 patients studied had primary amyloidosis (Table I). These patients did not have the bone marrow morphology associated with myeloma. They did not have lytic bone lesions, recurrent infections, or hypercalcemia. Renal biopsies showed

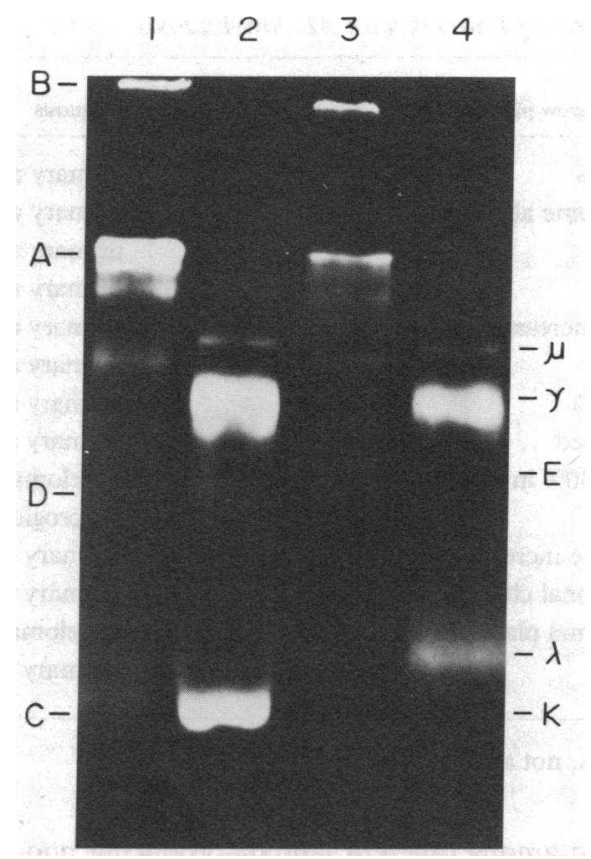

Figure 1. Equal amounts of lysates of cells from a patient with polyclonal hyperglobulinemia that had been incubated with radioactive amino acids, as described in Methods, were precipitated with antisera specific for kappa (lanes 1 and 2) or lambda (lanes 3 and 4) L-chains. The immune precipitates were dissolved in running buffer and electrophoresed on $0.1 \%$ SDS-containing polyacrylamide gels with (lanes 2 and 4 ) or without reduction.

(A) Comigrating with the murine $\mathrm{H}_{2} \mathrm{~L}_{2}$ marker, this band is precipitable with both anti-kappa and anti-lambda serum. It represents the normal population of polyclonal IgG molecules synthesized by the marrow. (B) Trapped at the top of the running gel in lanes 1 and 3, $B$ represents IgM. Reduction and alkylation of the precipitates yields two bands in the heavy chain region ( $\mu$ and $\gamma$ ) with both antisera and a single band in each L-chain region. In lane 2 the reduced and alkylated kappa band comigrates with the free excess kappa chains synthesized by the marrow cells $(C)$. A small amount of unreduced kappa dimer is also seen $(D)$. Band $E$, barely seen in lane 3, represents unreduced lambda dimers. The L-chain released by reduction and alkylation of the lambda precipitate migrates more slowly than the similarly treated kappa chain (35). In lane 1 an additional band, precipitable with both the kappa and lambda antisera and migrating with a mobility corresponding to a protein of $\sim 75,000 \mathrm{~mol}$ wt probably represents a heavy-light heterodimer. In other experiments not shown, it is also precipitable with an anti-gamma serum. The autoradiograms were overexposed in order to visualize molecules seen in trace amounts. Using this procedure, no molecules smaller than L-chains were seen in this or other similar experiments.

amyloid, not myeloma kidney. Two patients had myeloma with amyloid while one had macroglobulinemia.

All patients studied synthesized excess free Ig light chains (Table II). 10 patients produced lambda and 4 produced kappa. Monoclonal $\mathrm{H}_{2} \mathrm{~L}_{2}$ production was shown in patients 7 and 9 . Polyclonal $\mathrm{H}_{2} \mathrm{~L}_{2}$ production by normal bone marrow cells was also detected in most patients but not included in the table.

All patients except one (patient 10) had L-chain dimers in both cytoplasm and secretions (Table II). Among lambda producers, dimers were the dominant molecular species secreted during the 4- $\mathrm{h}$ incubation period. In cells secreting kappa chains, the monomer was always the prevalent form both intra- and extracellularly. Kinetic experiments indicated that the dimeri- 
Table I. Clinical Features of Patients with AL Amyloidosis

\begin{tabular}{rllll}
\hline Patient No. & Bone marrow plasma cells & Diagnosis & Major clinical feature & $\begin{array}{l}\text { Fibril } \\
\text { immunohistochemistry* }\end{array}$ \\
\hline 1 & $10-12 \%$ & primary amyloid & cardiac & NAł \\
2 & $10 \%$ some abnormal & primary amyloid & liver, renal & NA \\
3 & $1-2 \%$ & primary amyloid & lung mass & nonspecific \\
4 & $2-3 \%$ & primary amyloid & renal & lambda \\
5 & slight increase & primary amyloid & cardiac & lambda \\
6 & $30 \%$ & primary amyloid & pulmonary & NA \\
7 & $10-15 \%$ & primary amyloid & renal, carpal tunnel & lambda \\
8 & increased & primary amyloid & renal, coagulopathy & NA \\
9 & up to $30 \%$ in sheets & myeloma & myeloma & NA \\
10 & $6 \%$ & macroglobulinemia & neuropathy & kappa \\
11 & variable increase & primary amyloid & cardiac & lambda \\
12 & occasional clusters of $2-3$ plasma cells & primary amyloid & hepatomegaly malabsorption & NA \\
13 & abnormal plasma cells & myeloma & myeloma with cryoglobulin & NA \\
14 & $17 \%$ & primary amyloid & renal, bowel, skin & nonspecific
\end{tabular}

* Reference 17a. $¥$ NA, not available.

zation process varied among different lambda-producing populations. In some individuals, dimers exceeded monomers by $30 \mathrm{~min}$ of incubation, while in others dimers and monomers were present in similar concentrations at $4 \mathrm{~h}$. In most cases, however, at $4 \mathrm{~h}$ the dimers were the major species (Fig. 2).

Five of the patients synthesized molecules that were precipitable with anti-L-chain sera but were smaller in size than the intact L-chains (Figs. 2 and 3). The estimated molecular weights (mol wt) of the reduced fragments, as determined by the relative electrophoretic mobilities on these gels, ranged from 12,500 to 27,000 .

In patient 1 (Fig. 2), after $4 \mathrm{~h}$ of incubation the secreted material contained anti-lambda-precipitable material of 24,500 $(B)$ and 49,000 mol wt $(A)$ representing L-chain monomer and dimer, respectively. In the cytoplasm, additional bands of 23,000, 16,000 , and $<12,000 \mathrm{~mol} \mathrm{wt}$ were also noted (Fig. 2, lane 2). The latter two molecules were also precipitable with a polyclonal serum directed against $\beta_{\mathbf{2}}$ microglobulin but not with polyclonal anti-kappa serum (Fig. 2, lanes 3 and 4). Monoclonal antilambda serum precipitated only the $49,000,24,500$, and 23,000 mol-wt species. Hence it appears that the only apparent fragment $\left(\lambda_{F}\right)$ seen in this patient was $\sim 6 \%$ smaller than the intact $L$ chain. It did not appear to dimerize and was not found in significant quantities outside the cell during the observed incubation period.

Labeled cytoplasm and secretions from patient 6 contained three major anti-kappa-precipitable molecules, $\mathrm{H}_{2} \kappa_{2}, \kappa_{2}$, and $\kappa$, and a kappa protein of $27,000 \mathrm{~mol} \mathrm{wt}\left(\kappa_{\mathrm{F}}\right)$. Fig. 3, lane 1 shows that the dominant anti-kappa-precipitable cytoplasmic molecule is the kappa monomer $(A)$. A smaller amount of dimer is also seen (Fig. $3 B$ ) as is a faint band migrating more rapidly than the intact L-chain (C). In the secreted material the same bands are noted (Fig. 3, lane 3) as is a small amount of $\mathrm{H}_{2} \mathrm{~L}_{2}$. Anti-lambda precipitates (Fig. 3, lanes 2 and 4) show only barely detectable $\mathrm{H}_{2} \mathrm{~L}_{2}$. The positions of the molecular weight markers are noted. Similar findings were noted in patient 13 (not shown). The findings in patient 14 have been reported previously (18). Lambda tetramers were found both intra- and extracellularly. Reduction of the anti-lambda precipitates released a 10,00012,500 -mol-wt fragment not seen in the unreduced preparations.
Patient 11 had the most complex biosynthetic profile in the entire group of patients (Fig. 4). After $10 \mathrm{~min}$ of incubation the major cytoplasmic molecule had a relative molecular mass of 47,000 and represents $\lambda_{2}$ (Fig. $4 A$ ). A smaller amount of lambda monomer (Fig. $4 \mathrm{~B}$ ) is seen. At later times a $15,000-\mathrm{mol}-w \mathrm{t}$ anti-lambda-precipitable polypeptide is also found (Fig. $4 \mathrm{C}$ ). In samples prepared from the 10,30,45, and 60-min cytoplasms an additional band is noted (Fig. $4 \mathrm{D}$ ) with an estimated molecular weight of 42,000 . It appears to represent a monomerfragment heterodimer $\left(\lambda \lambda_{F}\right)$. It is found in the secretions and seems to diminish in the cytoplasm with kinetics similar to the $\lambda_{2}$ dimer (Fig. $5 A$ and $B$ ). At $60 \mathrm{~min}$ of continuous labeling the dimer represented $53 \%$ of the lambda-precipitable material, the monomer $25 \%$, the fragment $12 \%$, and the fragment dimer $10 \%$. After $4 \mathrm{~h}$, the monomer comprises $45 \%$, the dimer $30 \%$, the fragment $24 \%$, and the fragment dimer $<1 \%$. Since the experiment was not carried out with a cold amino acid chase it was difficult to establish precursor-end product relationships and to totally exclude the possibility of rapid partial proteolysis of a normal precursor.

Unreduced immunoprecipitated secreted material from patient 11 is shown in Fig. 6, lane 1 . While both the unreduced intra- and extracellular material contain proteins of 47,000 (Fig. $6 \mathrm{~A}$ ) and $42,000 \mathrm{~mol}$ wt (Fig. $6 \mathrm{D}$ ), the secretions also contain a 30,000-mol-wt (Fig. $6 E$ ) molecule not present inside the cells. The cytoplasm contains molecules of 27,000 mol wt (Fig. 4 B) and 15,000 mol wt (Fig. $4 C$ ) not seen extracellularly. Despite these differences in the unreduced precipitates, reduction of both yields the same two polypeptides of 27,000 and $15,000 \mathrm{~mol} \mathrm{wt}$, respectively (Fig. 6, lanes 2 and 3, $B_{R}$ and $C_{R}$ ). The larger represents the alkylated lambda monomer while the smaller is an incomplete lambda chain. Hence, all the intracellular and extracellular lambda-containing molecules represent disulfidelinked homo or heteropolymers of these two peptides, i.e., $\lambda_{2}$ at $47,000 \mathrm{~mol} \mathrm{wt}, \lambda \lambda_{F}$ at $42,000 \mathrm{~mol} \mathrm{wt}$, and $\left(\lambda_{F}\right)_{2}$ at $30,000 \mathrm{~mol}$ wt. Since only dimers are found extracellularly and monomers are readily detectable inside the cell, it is likely that the free SH groups are either blocked by cellular SH donors or that intracellular conditions provide a reducing environment.

Since the precipitations in all the experiments reported here 


\begin{tabular}{|c|c|c|c|c|c|c|}
\hline \multirow[b]{2}{*}{ Patient No. } & \multirow[b]{2}{*}{ Serum } & \multirow[b]{2}{*}{ Urine } & \multicolumn{2}{|l|}{ Cytoplasm } & \multicolumn{2}{|l|}{ Secretions } \\
\hline & & & Structure* & & Structure & \\
\hline & & & & $M_{r} \ddagger$ & & $M_{\mathbf{r}}$ \\
\hline \multirow[t]{3}{*}{1} & Нypo- $\gamma$ & $? \lambda$ & $\lambda_{2}$ & 49,000 & $\lambda_{2}$ & 49,000 \\
\hline & & & $\lambda$ & 24,500 & $\lambda$ & 24,500 \\
\hline & & & $\lambda_{\mathbf{F}}$ & 23,000 & & \\
\hline \multirow[t]{2}{*}{2} & Monoclonal $\operatorname{Ig} A_{\lambda}$ & $\alpha, \lambda$ & $\lambda_{2}$ & 43,000 & $\lambda_{2}$ & 43,000 \\
\hline & & & $\left(\alpha_{\mathrm{F}}\right)_{2}$ & $72-84,000$ & $\left(\alpha_{\mathrm{F}}\right)_{2}$ & $80-84,000$ \\
\hline \multirow[t]{2}{*}{3} & Oligoclonal IgG & - & $\kappa_{2}$ & 43,000 & $\kappa_{2}$ & 43,000 \\
\hline & & & $\kappa$ & 23,000 & $\kappa$ & 23,000 \\
\hline 4 & Monoclonal IgG & $\operatorname{IgG}_{\lambda}$ & $\lambda_{2}$ & $50-51,000$ & $\lambda_{2}$ & $50-51,000$ \\
\hline \multirow[t]{2}{*}{5} & Trace free $\lambda$ & - & $\lambda_{2}$ & 44,000 & $\lambda_{2}$ & 44,000 \\
\hline & & & $\lambda$ & 23,000 & $\lambda$ & 23,000 \\
\hline \multirow[t]{3}{*}{6} & Нуро- $\gamma$ & $\kappa$ & $\kappa_{2}$ & 59,000 & $\kappa_{2}$ & 59,000 \\
\hline & & & $\kappa$ & 32,000 & $\kappa$ & 32,000 \\
\hline & & & $\kappa_{F}$ & 27,000 & $\kappa_{F}$ & 27,000 \\
\hline \multirow[t]{3}{*}{7} & Monoclonal $\operatorname{IgG}_{\lambda}$ & $\lambda$ & $\gamma_{2} \lambda_{2}$ & 155,000 & $\gamma_{2} \lambda_{2}$ & 150,000 \\
\hline & & & $\lambda_{2}$ & 43,000 & $\lambda_{2}$ & 43,000 \\
\hline & & & $\lambda$ & 22,000 & $\lambda$ & 22,000 \\
\hline \multirow[t]{2}{*}{8} & Нуро- $\gamma$ & $\lambda$ & $\lambda_{2}$ & 46,000 & $\lambda_{2}$ & 46,000 \\
\hline & Free $\lambda$ & & $\lambda$ & 23,000 & $\lambda$ & 23,000 \\
\hline \multirow[t]{3}{*}{9} & Monoclonal cryoglobulin $\operatorname{IgG}_{\kappa}$ & $\operatorname{lgG}_{k}$ & $\gamma_{2} \kappa_{2}$ & 150,000 & $\gamma_{2} \kappa_{2}$ & 150,000 \\
\hline & & & $\kappa_{2}$ & 45,000 & $\kappa_{2}$ & 45,000 \\
\hline & & & $\kappa$ & 23,500 & $\kappa$ & 23,500 \\
\hline \multirow[t]{2}{*}{10} & Hypo- $\gamma$ & - & $\kappa_{2}$ & 48,000 & & \\
\hline & & & $\kappa$ & 23,000 & $\kappa$ & 23,000 \\
\hline \multirow[t]{4}{*}{11} & Нypo- $\gamma$ & trace $\lambda$ & $\lambda_{2}$ & 47,000 & $\lambda_{2}$ & 47,000 \\
\hline & & & $\lambda \lambda_{F}$ & 42,000 & $? \lambda \lambda_{F}$ & 42,000 \\
\hline & & & $\lambda$ & 27,000 & $\left(\lambda_{\mathrm{F}}\right)_{2}$ & 30,000 \\
\hline & & & $\lambda_{F}$ & $12-15,000$ & & \\
\hline \multirow[t]{2}{*}{12} & $\operatorname{IgM}_{\lambda}$ & $\lambda$ & $\lambda_{2}$ & 40,000 & $\lambda_{2}$ & 40,000 \\
\hline & & & $\lambda$ & 25,000 & $\lambda$ & 25,000 \\
\hline \multirow[t]{4}{*}{13} & Нypo- $\gamma$ & $\lambda$ & $\lambda_{2}$ & 44,000 & $\lambda_{2}$ & 44,000 \\
\hline & & & $\lambda$ & 21,000 & $\left(\lambda_{F}\right)_{2}$ & 38,000 \\
\hline & & & & & $\lambda$ & 24,000 \\
\hline & & & & & $\lambda_{F}$ & 19,000 \\
\hline \multirow[t]{3}{*}{14} & Нуро- $\gamma$ & $\lambda$ & $\lambda_{4}$ & $100-110,000$ & $\lambda_{4}$ & $100-110,000$ \\
\hline & $\lambda$ Polymer & & $\lambda_{2}$ & 56,000 & $\lambda_{2}$ & 56,000 \\
\hline & & & & & $\lambda_{F}$ & $10-12,500$ \\
\hline
\end{tabular}

* Structures deduced from comparison of electropherograms of immunologically precipitated material in the reduced and unreduced state (see Methods and Fig. 1).

$\ddagger M_{\mathrm{r}}$, molecular weight estimated by electrophoretic mobility relative to marker proteins (see legend to Fig. 2).

were carried out with anti-constant region sera, fragments containing only V-region determinants would have been missed. A few samples have been studied with anti-V-region sera provided by Dr. Alan Solomon, University of Tennessee Health Sciences Center, Knoxville, TN. (10). To date, these have not detected fragments that were not precipitable with the anti-constant region sera.

In one experiment the synthesis of an alpha heavy chain fragment was noted. The patient (patient 2) exhibited none of the clinical features associated with any of the reported cases of alpha heavy chain disease (19). Tissue was not available for the analysis of his amyloid deposits to determine if alpha chain comprised any portion of the fibrillar material.
We examined several marrows obtained from patients with biopsy-documented $\mathrm{AL}$ disease in whom no serum or urine $\mathbf{M}$ protein could be detected. Serum and urine studies from one such individual are shown in Fig. 7. Biosynthetic studies of the patients' bone marrow cells are shown in Fig. 8. The cytoplasm clearly contained free kappa chains and kappa dimers. Hence, despite the absence of a monoclonal serum or urine protein, we could demonstrate bone marrow biosynthesis of excess monoclonal L-chains that corresponded to those found deposited in tissues on biopsy. Studies were performed with bone marrow cells obtained from this patient on two occasions 4 mo apart. The results of both studies were similar, apart from a difference in the amount of secreted L-chain monomers. The amount of 


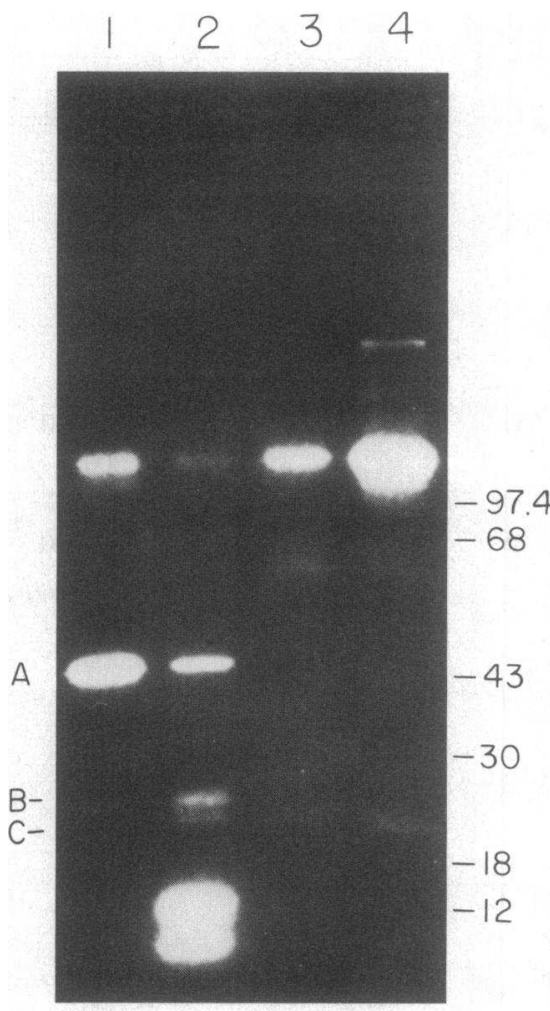

Figure 2. Anti-kappa (lanes 3 and 4) and anti-lambda (lanes 1 and 2) immune precipitates were prepared from 1-h radiolabeled cytoplasm (lanes 2 and 4) and 4-h secretions (lanes $l$ and 3) from patient 1 and electrophoresed in nonreducing gels as described in Methods. The positions of the molecular weight markers are noted. $\mathrm{H}_{2} \mathrm{~L}_{2}$ is seen in all the lanes. $\lambda_{2} A$ and $\lambda B$ are seen in lanes $l$ and 2 . A smaller lambda protein is seen only in lane 2 (see text). The low molecular weight bands seen in lane 2 were also precipitable with an anti- $\beta_{2} \mathbf{M}$ serum, hence do not represent L-chain-related molecules. Labeled marker proteins, obtained from New England Nuclear, included phosphorylase B, $97,400 \mathrm{~mol}$ wt; bovine serum albumin, $68,000 \mathrm{~mol} \mathrm{wt}$; ovalbumin, 43,000 mol wt; carbonic anhydrase, $30,000 \mathrm{~mol} \mathrm{wt}$; lactoglobulin A, $18,400 \mathrm{~mol} \mathrm{wt}$; and cytochrome C $12,300 \mathrm{~mol} \mathrm{wt}$.

free L-chain secreted by the cells during the labeling period was small.

A number of reports have suggested that some $A L$ patients may respond to drugs that are effective in the therapy of multiple myeloma $(18,20,21)$. We have studied several who have been treated with such regimens. The results of one such analysis are shown in Fig. 9. Before therapy, (Fig. $9 \mathrm{~A}$ ) the marrow cells of the patient (patient 11) (see above) synthesized and secreted a normal sized lambda chain, its dimer, a lambda fragment, and its dimer. Time-course studies suggested that the fragment was not the result of intracellular proteolysis (Figs. 4 and 5). In addition, the marrow cell population produced virtually no free kappa chains and only small amounts of $\mathrm{H}_{2} \mathrm{~L}_{2}$-containing kappa chains.

Cells obtained from the same patient 9 mo later, after monthly courses of cytotoxic agents and prednisone, were labeled and analyzed in a similar fashion. Fig. $9 B$ shows that the marrow cells no longer synthesized free lambda chain or fragments. The marrow now synthesized both kappa- and lambda-containing $\mathrm{H}_{2} \mathrm{~L}_{2}$ in a ratio of approximately $3: 2$, hence approximating the pattern seen when normal bone marrow cells are studied using these techniques (Fig. 1).

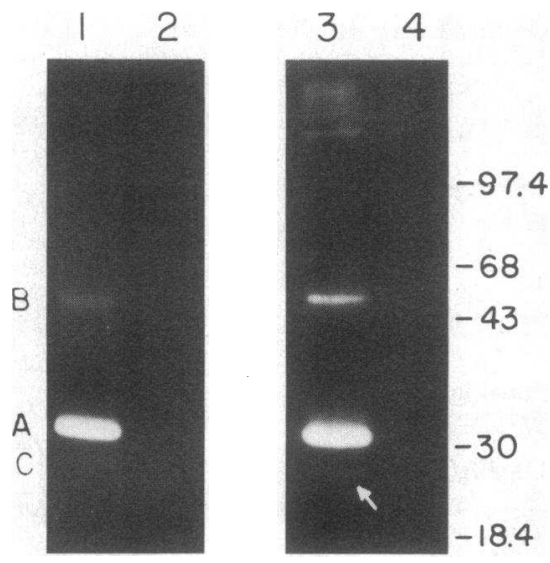

Figure 3. Cytoplasmic lysates were prepared from the bone marrow cells of patient 6 after $1 \mathrm{~h}$ of incubation with radioactive amino acids. Secretions were collected over a 4-h incubation period. Samples were immunologically precipitated and electrophoresed as described in Methods. Lanes 2 and 4 contain anti-lambda precipitates of cytoplasm and secretion while lanes 1 and 3 contain anti-kappa precipitates of cytoplasm and secretions, respectively. Kappa dimers $(59,000$ $\mathrm{mol} \mathrm{wt}$ ), monomers (32,000 mol wt), and a related polypeptide (arrow) are seen. In this case the estimated molecular weights of the kappa chain and its dimer are larger than expected. Whether this represents an electrophoretic artifact or a true increase in molecular size due to the synthesis of a large peptide or excessive glycosylation could not be determined (30).

\section{Discussion}

These studies show that bone marrow cells obtained from all the patients with biopsy-documented AL amyloidosis synthesized

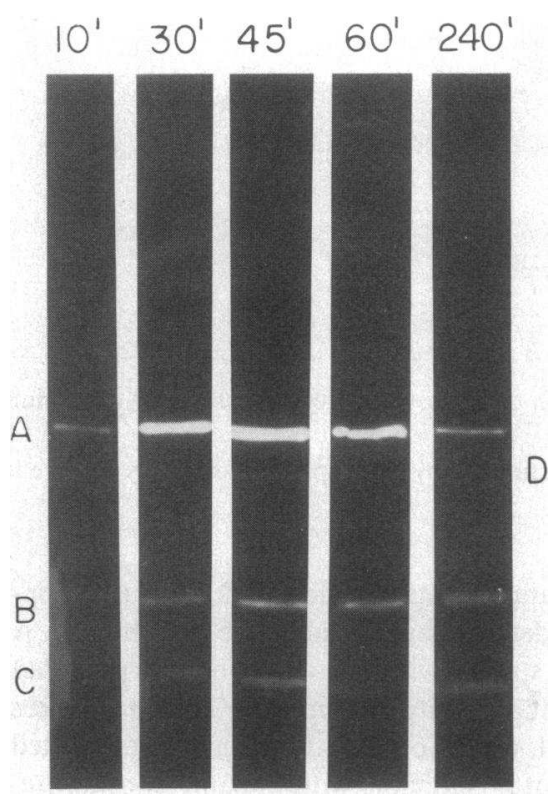

Figure 4. Anti-lambda precipitates were prepared from cytoplasmic lysates of patient 11 that had been labeled for $10,30,45,60$, and 240 $\mathrm{min}$. The precipitates were dissolved and electrophoresed as described in Methods. $A$ represents lambda dimer, $B$, lambda monomer, and $C$, a lambda fragment $\left(\lambda_{F}\right)$. $D$ has a mobility corresponding to a molecular weight of $42,000 \mathrm{~mol} \mathrm{wt}$, probably representing a $\lambda \lambda_{F}$ heterodimer. The positions of the marker proteins run on the gel are not shown. 

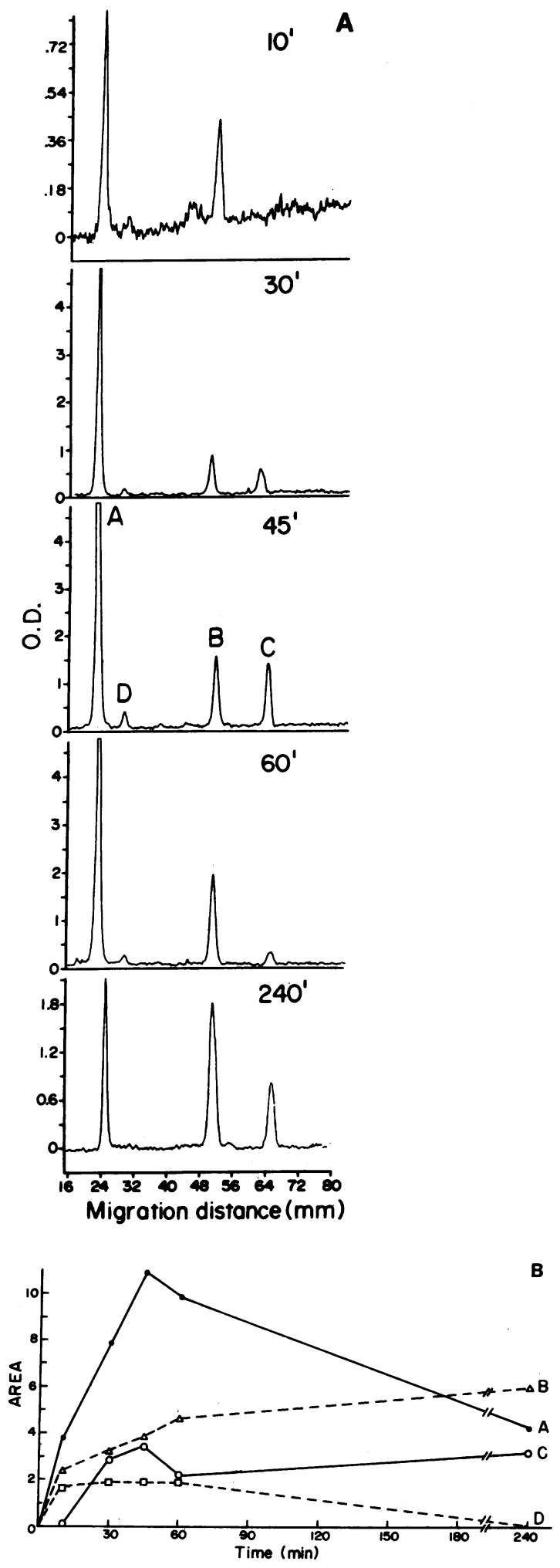

Figure 5. (A) Laser densitometer tracings of the fluorograms shown in Fig. 4. The four immunologically precipitable molecules readily seen in the 30-, 45-, and 60-min samples are present in all the samples, but $C$ and $D$ are lost in the background of the 10 sample because of the lower signal-to-noise ratio. The letters $A, B, C$, and $D$ correspond to those noted on the gel in Fig. 4. $(B)$ The areas under each peak of Fig. $5 A$ were determined by computer integration of the tracings and plotted as arbitrary units of area against time. Since the experiment involved continuous labeling rather than a pulse and chase it is not pos-

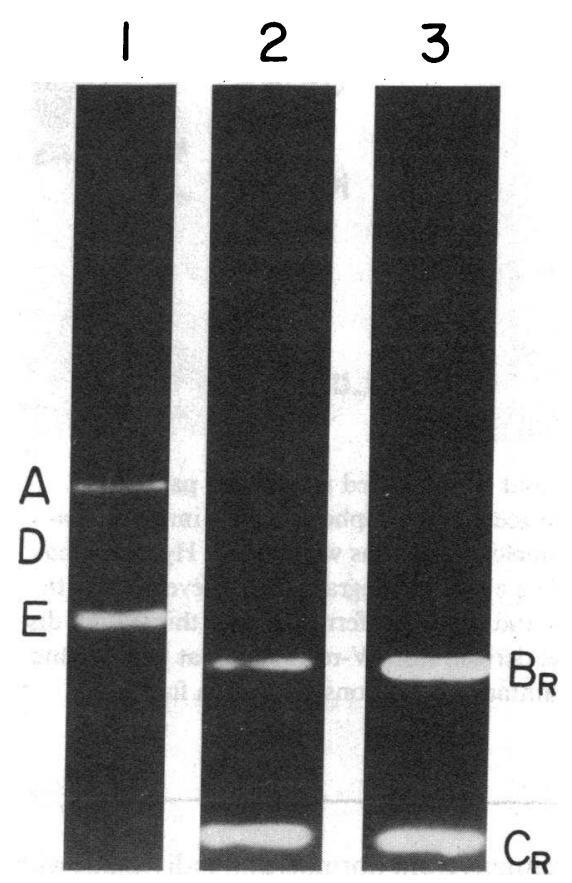

Figure 6. Lane 1 shows the gel pattern of an anti-lambda precipitate of material secreted by the bone marrow cells of patient 11 . As in Fig. $4, A$ represents $\lambda_{2}$, and $D$, the heterodimer. $E$, not seen in the cytoplasm, is the fragment dimer. Lanes 2 and 3 are the patterns seen when the anti-lambda precipitates of cytoplasm (lane 2) and secretions (lane 3 ) are reduced and alkylated yielding two molecular species of $27,000 \mathrm{~mol} \mathrm{wt}\left(B_{R}\right)$ and $15,000 \mathrm{~mol} \mathrm{wt}\left(C_{R}\right)$, respectively.

free L-chains. Patients 3, 5, and 10 had no detectable free $\mathrm{L}$ chains in the urine, although patient 5 did have trace amounts in the serum. Patients 1 and 11 had barely detectable quantitities, found only after the urine was highly concentrated. Patients 4 and 9 had monoclonal IgG proteins in the serum and in the urine as part of a glomerular pattern of nephrotic proteinuria. However, no free L-chains could be found. The detection of free L-chain synthesis by bone marrow cells of patients with only intact $\mathrm{H}_{2} \mathrm{~L}_{2}$ proteins in the serum and urine, and in those individuals with no monoclonal $\mathrm{H}_{2} \mathrm{~L}_{2}$ or free L-chains detectable by conventional clinical means, clearly indicates that the tissue deposits can be derived from primary L-chain synthetic products and that in vivo reductive or proteolytic release of $L$-chains from $\mathrm{H}_{2} \mathrm{~L}_{2} \mathrm{M}$ proteins need not be hypothesized.

The usefulness of the biosynthetic technique is best demonstrated in patients of this type, i.e., possessing biopsy-proven, amyloid-positive tissues, with no definable serum or urine monoclonal protein present. Fig. 7 shows conventional electrophoretic and immunoelectrophoretic analyses from one such patient that reveal no monoclonal Igs or L-chains. Analysis of cytoplasm revealed monoclonal kappa production (Fig. 8). Bone marrow cells from patients without myeloma or AL disease synthesize free L-chains (Fig. 1). These can be demonstrated in

sible to determine precursor-end product relationships. It is clear, however, that the lambda fragment, $C$, and lambda monomers, $B$, continue to accumulate in the cytoplasm between 1 and $4 \mathrm{~h}$ while the lambda dimers, $A$, and the $\lambda \lambda_{\mathrm{F}}$ heterodimer, $D$, diminish. The fragment dimer was not detectable in the cytoplasm. 


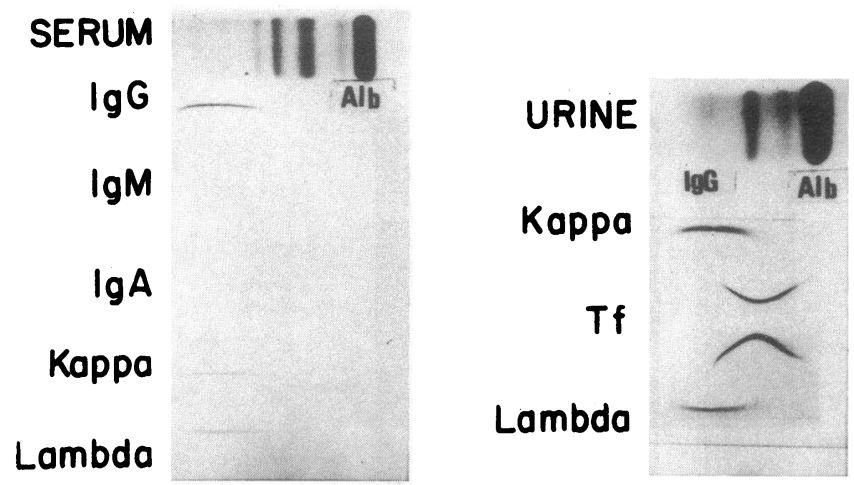

Figure 7. Serum and 400-fold concentrated urine from patient 10 were subjected to cellulose acetate electrophoresis with immunofixation as described. No monoclonal proteins were noted. Hypogammaglobulinemia is evident. The electropherograms were developed with anti-Ig heavy and L-chain and anti-transferrin sera. In this system discrete Ig L-chain fragments derived from V-regions run at the extreme cathodal portion of the gamma region. Constant region fragments tend to run anodally.

concentrated urine specimens from normals and individuals with polyclonal hyperglobulinemia (22). We have studied a small number of such individuals and demonstrated the presence of L-chain monomers and dimers of both kappa and lambda classes in a ratio of $\sim 3: 2$ with no immunologically precipitable species smaller than the size of intact L-chains detectable. Most AL patients synthesize lambda proteins so that reversal of the kappa/ lambda ratio in the L-chains synthesized in short-term tissue culture is probably significant. Further, normal Ig synthesis is usually suppressed in these patients. Hence, the use of the bio-

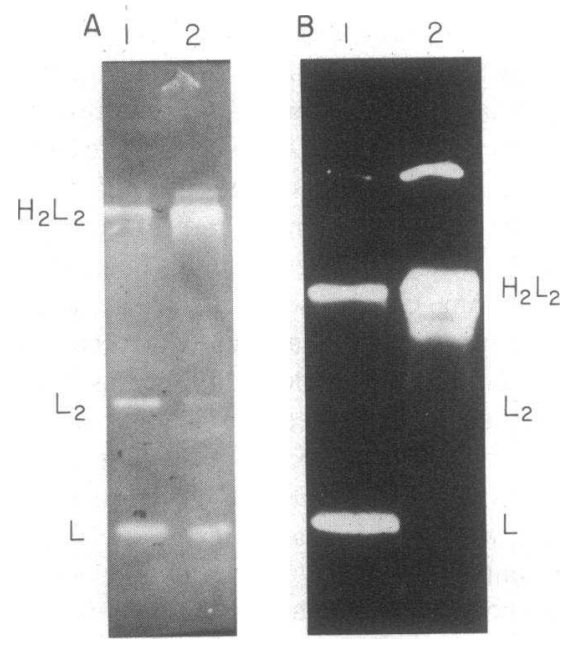

Figure 8. Cells obtained from patient 10 were radiolabeled on two occasions 4 mo apart $(A$ and $B)$. Cytoplasm $\left(\mathrm{A}_{1}\right.$ and $\left.\mathrm{B}_{1}\right)$ and secreted $\left(\mathrm{A}_{2}\right.$ and $B_{2}$ ) samples were precipitated with anti-kappa sera. The precipitates were dissolved and electrophoresed as described. On both occasions the cells contained $\mathrm{H}_{2} \mathrm{~K}_{2}, \mathrm{~K}_{2}$, and $\mathrm{K}$ while the secretions contained $\mathrm{H}_{2} \mathrm{~K}_{2}$ and a small amount of kappa dimers. Comparisons of lanes $A_{2}$ and $B_{2}$ indicate that the secretions contained a smaller amount of free L-chains at the time of the second bone marrow. It is not clear whether this diminution in the quantity of free L-chains in the secretions was a function of a variation in the labeling protocol or was biologically significant.

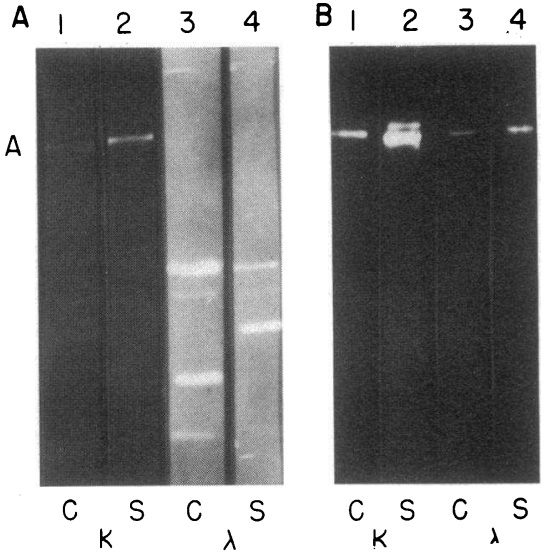

Figure 9. Bone marrow cells from patient 11 were analyzed as described in Methods on two occasions 9 mo apart. The patient received monthly courses of cytotoxic therapy during the intervening period. The pretreatment analyses $(A)$ show small amounts of $\mathrm{H}_{2} \mathrm{~K}_{2}$ in both the cytoplasm and secretions (lanes $l$ and 2). Precipitation with antilambda serum shows the cytoplasmic and secreted molecules described in Figs. 4 and 5 and the text (lanes 3 and 4 ). After therapy $(B)$ kappa- and lambda-containing $\mathrm{H}_{2} \mathrm{~L}_{2}$ molecules are present in increased amounts with more kappa-containing molecules than lambda. No free L-chains or fragments of either class are noted in the posttreatment marrow.

synthetic assay as an analytic tool increased the demonstrable presence of monoclonal L-chains in AL disease to $100 \%$. Tissue deposition of these molecules in the absence of readily detectable serum or urine proteins may reflect relatively low synthetic and secretory rates coupled with the putative high affinity of the Lchains or their fragments for tissue sites (23).

We have previously reported changes in the spectrum of Igrelated molecules in a patient treated with a protocol similar to that used in the therapy of multiple myeloma (18). In that patient, clinical improvement was associated with a change in Ig synthesis. Patient 11 demonstrates a similar result. The patient's urine contained only trace amounts of a monoclonal lambda $\mathrm{L}$ chain. Gingival biopsy revealed amyloid with lambda determinants demonstrable immunohistochemically (17a). Biosynthetic studies at the time of diagnosis showed both qualitative and quantitative L-chain abnormalities. Repeat analyses 9 mo later, after monthly courses of melphalan and prednisone, showed an essentially normal biosynthetic pattern with no excess L-chain production and $\mathrm{H}_{2} \mathrm{~L}_{2}$ synthesis with a kappa/lambda ratio of roughly $3: 2$. Hence, therapy was accompanied by normalization in the pattern of Ig biosynthesis both quantitatively and qualitatively, suggesting elimination of the monoclonal plasma cell population responsible for synthesis. Fig. 8 shows similar analyses in a patient who showed no clinical response. In this case the difference in the amount of L-chain monomer synthesized may represent an effect of therapy or a result of variation in the labeling protocol. These data demonstrate that biosynthetic analyses can be utilized to monitor patients' responses to therapy.

Scattered case reports suggest that some patients with $A L$ disease have increased survival when treated with melphalan and prednisone $(18,20,21)$. It seems unlikely that patients will improve if there is no reduction in free L-chain synthesis, hence biochemical responsiveness might be used to predict the potential clinical efficacy of these drug regimens. If there is no evidence of alteration of Ig synthesis after a 6-12-mo course of drug, it is 
unlikely that alteration would occur later. It would seem pointless to expose the patient to a regimen with side effects that include neoplasia $(24,25)$.

It is important to ask two further questions concerning the genesis of the smaller L-chain-related molecules synthesized. The first question concerns the relationship between the synthetic fragments and the tissue deposits in a given individual. Will the fibrillar material contain all the synthesized molecular species in proportions similar to that found in the synthesizing cells or will the fragments be selectively deposited? Will the major fibrillar subunit reflect some degree of in situ processing as has been suggested by a number of investigators (10)? Analysis of the fibrillar material isolated from tissues of patient 14 revealed major components of $\sim 25,000$ and $12,500 \mathrm{~mol} \mathrm{wt}$, sizes similar to the polypeptides synthesized by his bone marrow cells (25a). Since synthesis of smaller molecules could be detected in only one-third of our subjects, it is clear that some other process (e.g., tissue proteolysis) may be responsible for the remainder. However, it must be noted that until recently we have not had access to anti-V-region sera and some of these patients may have been synthesizing V-fragments that were not detectable with anticonstant region sera.

If, in most patients, the deposited and synthetic fragments are not identical in size, particularly if the tissue fragments are smaller, it may be that the aberrant peptides are more predisposed to deposition with further proteolytic processing than are intact chains, hence are favored precursors for deposition. If the deposited fragments are larger than the synthetic fragment, it would imply either that the deposits are comprised exclusively of processed intact chains or that the smaller fragments have polymerized during deposition. In any case, the discovery of the synthesis of L-chain fragments in AL disease forces us to reexamine the pathogenesis of tissue deposition. It is likely that several processes may be involved, with some intact chains, e.g., $V \lambda_{\mathbf{V I}}$, susceptible to deposition after simple proteolysis while synthetic fragments of others are directly deposited.

The second question relates to the synthetic relationships between the intact chains and the smaller molecules. Immunologically, these represent related molecules; however, we have not formally established by sequence analysis that the proteins actually use the same V-regions. In those cases (1 and 6) in which the mobility differences are small, it is possible that they represent glycosylated and unglycosylated forms of the same $\mathbf{L}$ chain. It has been estimated that $15 \%$ of human Ig L-chains have $N$-linked carbohydrate moieties $(26,27)$. We have not systematically studied each of the marrows for their capacity to incorporate labeled sugars into Ig heavy and light chains. If the $15 \%$ estimate is correct and there is no relationship between $\mathrm{AL}$ disease and light chain carbohydrate, then 2 of 14 L-chains might be expected to be glycosylated and the small proteins found in patients 1 and 6 could represent the unglycosylated form in the statistically predicted sample. Hence, the latter remains a possible explanation unrelated to the pathogenesis of tissue deposition.

The heterogeneity of synthetic products, whether they are fragments or differentially glycosylated intact chains, could represent the synthesis of different related Ig molecules by different subclones of the same L-chain-producing clone, since the labeling techniques reflect the average behavior of the marrow cell population being analyzed. We have studied one individual with myeloma without amyloid in whom we could identify two intact $\mathrm{IgG}_{\mathbf{k}}$ molecules, only one of which had a glycosylated light chain (Goni, F., B. Frangione, and J. Buxbaum, unpublished observations). In that case the reduced and alkylated light chains had mobilities on SDS gels equivalent to a difference in molecular weights of $\sim 3,500$. Both IgG molecules were isolated from serum and the amino acid sequences of the L-chains determined. These data indicated that the two molecules were the products of separate clones, an observation more consistent with a disease associated with a substantial proliferating pool of cells. We view this as unlikely in the AL cases, since the clonal proliferations we have studied appear to be rather limited, thus they would have fewer divisions in which to generate variants. A comparison between Tables I and II reveals no association between the clinical picture of neoplasia, i.e., multiple myeloma, and the presence of small molecules bearing light L-chain antigenic determinants.

Alternatively, the fragments might represent proteins coded by different L-chain genes. That this appears to be unlikely is indicated by structural studies of deposited proteins that seem to demonstrate identical amino-termini in those fragments that have been analyzed. However, this is still a possibility. The fragments may represent the products of transcripts from a normally rearranged gene that contains abnormal termination signals. These would result in normal $\mathrm{NH}_{2}$ termini but aberrant $\mathrm{COOH}$ termini (28). It is also possible that the fragments that we are detecting are the protein products of $\mathrm{COOH}$ region transcripts containing little or no V-sequence and are irrelevant to the tissue deposition of Ig that marks these patients. In murine tumors of the $B$ and $T$ lineages a number of instances have now been reported in which aberrant peptides have been synthesized using templates that represent abnormal transcripts either from the same chromosome coding for the major cell product or from the other, incorrectly rearranged, chromosome (29).

Over the years a number of reports have appeared describing human L-chain proteins that vary in size from the prototype structures. Molecules that are apparently larger than normal have been analyzed, but not in sufficient detail to establish what they represent vis-à-vis normal L-chain structure. A few have been found to be normal size peptides that are relatively heavily glycosylated. It has been assumed, but not established, that the others are extended peptides (30). The protein synthesized by patient 6 may represent such a molecule.

More relevant to the present work are the descriptions of smaller polypeptides bearing L-chain determinants that are antigenically deficient relative to normal L-chains of the same class $(31,32)$. Most of these have been isolated from the urine of patients with multiple myeloma, with at least one investigator finding these fragments in about one-third of the urinary Lchain preparations examined. Their frequent occurrence coupled with their absence from serum have suggested that they arise through the action of serum or urine proteases. It has not been noted whether the fragments have been isolated from individuals with amyloidosis.

We have not seen fragments in labeling experiments in cells obtained from polyclonal hyperglobulinemic marrows (Fig. 1) and patients with myeloma or macroglobulinemia. We have had no difficulty, as have others, in identifying fragments in human heavy chain diseases, and monoclonal Ig deposition disease, a condition in which intact Ig chains or related polypeptides are deposited in tissues, although without the fibril formation that is the morphologic sine qua non of amyloidosis $(33,34)$. It is possible that analysis of synthesis in $\mathrm{AL}$ and monoclonal Ig deposition disease patients will provide further insights into the regulation of expression of human Ig genes. At the moment, however, it appears that the analysis of the molecules synthesized by their bone marrow cells is clinically useful both for diagnostic purposes and for monitoring therapeutic intervention. 


\section{Acknowledgments}

The author would like to acknowledge the cooperation of the following physicians: Dr. Edward Amorosi, Dr. Ariel Distenfeld, Dr. Bruce Raphael, Dr. Gerard Hellman, and Dr. Hal Mitnick who skillfully managed the clinical care of these extremely ill patients. I would like to thank Dr. Gloria Gallo for her expert interpretation of the biopsy material, and Dr. Joseph Chuba for his perceptive and detailed analysis of the serum and urine proteins. Ms. Carol O'Brien prepared the manuscript with her usual expertise and affability. We appreciate the cooperation of Dr. John Thomas of the Department of Biochemistry who allowed us the use of the laser densitometer and its attendant software for the analysis of the data obtained from patient 11. Ms. Laurie Volk and Mr. Herb Koch provided their artistic expertise in the preparation of the figures.

These studies were supported by merit review research funds from the Veteran's Administration and the National Institutes of Health (AM14031).

\section{References}

1. Glenner, G. G., W. Terry, M. Harada, C. Isersky, and D. Page. 1971. Amyloid fibril proteins: proof of homology with immunoglobulin light chains by sequence analyses. Science (Wash. DC). 172:1150-1151.

2. Kyle, R. A., and P. R. Greipp. 1983. Amyloidosis (AL) Clinical and laboratory features in 229 cases. Mayo. Clin. Proc. 58:665-683.

3. Terry, W. D., D. L. Page, S. Kimura, T. Isobe, E. F. Osserman, and G. G. Glenner. 1973. Structural identity of Bence Jones and amyloid fibril proteins in a patient with plasma cell dyscrasia and amyloidosis. J. Clin. Invest. 52:1276-1281.

4. Putnam, F. W., E. J. Whitley, Jr., C. Paul, and J. N. Davidson. 1973. Amino acid sequence of $a \times$ Bence Jones protein from a case of primary amyloidosis. Biochemistry. 12:3763-3780.

5. Lian, J. B., M. Skinner, M. D. Benson, and A. S. Cohen. 1977. Fractionation of primary amyloid fibrils. Characterization and chemical interaction of the subunits. Biochim. Biophys. Acta. 491:167-176.

6. Glenner, G. G. 1980. Amyloid deposits and amyloidosis. N. Engl. J. Med. 302:1283-1293; 1333-1343.

7. Husby, G., K. Sletten, N. Blumenkrantz, and L. Danielsen. 1981. Characterization of an amyloid fibril protein from localized amyloidosis of the skin as $\lambda$ immunoglobulin light chains of variable subgroup I (V $\left.\lambda_{1}\right)$. Clin. Exp. Immunol. 45:90-96.

8. Natvig, B., P. Westermark, K. Sletten, G. Husby, and T. Michaelsen. 1981. Further structural and antigenic studies of light-chain amyloid proteins. Scand. J. Immunol. 14:89-94.

9. Pras, M., B. Frangione, and J. Gafni. 1982. Idiopathic AL-k amyloidosis presenting as giant hepatomegaly. Isr. J. Med. Sci. 18:866869.

10. Solomon, A., B. Frangione, and E. C. Franklin. 1982. Bence Jones proteins and light chains of immunoglobulins. J. Clin. Invest. 70: 453-460.

11. Chuba, J. V. 1979. Microimmunoelectrophoresis with improved resolution. J. Appl. Biochem. 1:37-50.

12. Amicon Corporation. 1983. Products for Separation-Minicon Concentrators. Publication No. 553. 37-38.

13. Phillips, H. J., and J. E. Terryberry. 1957. Counting actively metabolizing tissue cultured cells. Exp. Cell Res. 13:341-347.

14. Borun, T. W., M. D. Scharff, and E. Robbins. 1967. Preparation of mammalian polyribosomes with the detergent Nonidet P-40. Biochim. Biophys. Acta. 149:302-304.

15. Mans, R. J., and G. D. Novelli. 1961. Measurement of the incorporation of radioactive amino acids into protein by a filter paper disc method. Arch. Biochem Biophys. 94:48-53.

16. Kessler, S. W. 1975. Rapid isolation of antigens from cells with a staphylococcal protein A-antibody adsorbent: parameters of the interaction of antibody-antigen complexes with protein A. J. Immunol. 115: 1617-1624.
17. Bonner, W. M., and R. A. Laskey. 1974. A film detection method for tritium labelled proteins and nucleic acids in polyacrylamide gels. Eur. J. Biochem. 46:83-88.

17a. Gallo, G. R., H. D. Feiner, J. V. Chuba, D. Beneck, P. Marion, and D. H. Cohen. 1986. Immunohistochemical characterization of amyloid. Clin. Immunol. Immunopathol. 39:479-490

18. Buxbaum, J. N., M. E. Hurley, J. Chuba, and T. Spiro. 1979. Amyloidosis of the AL type. Clinical, morphologic and biochemical aspects of the response to therapy with alkylating agents and prednisone. Am. J. Med. 67:867-878.

19. Seligmann, M. 1975. Immunochemical, clinical, and pathological features of $\alpha$-chain disease. Arch. Intern. Med. 135:78-82.

20. Jones, N. F., P. J. Hilton, J. R. Tighe, and J. R. Hobbs. 1972. Treatment of "primary" renal amyloidosis with melphalan. Lancet. ii:616-619.

21. Cohen, H. J., L. A. Lessin, J. Hallal, and P. Burkholder. 1975. Resolution of primary amyloidosis during chemotherapy. Studies in a patient with nephrotic syndrome. Ann. Intern. Med. 82:466-473.

22. Waterhouse, C., G. Abraham, and J. Vaughan. 1973. The relationship between L-chain synthesis and $\gamma$-globulin production. J. Clin. Invest. 52:1067-1077.

23. Isobe, T., and E. F. Osserman. 1974. Patterns of amyloidosis and their association with plasma-cell dyscrasia, monoclonal immunoglobulins and Bence-Jones proteins. N. Engl. J. Med. 290:473-477.

24. Rosner, F., and H. Grunwald. 1974. Multiple myeloma terminating in acute leukemia. Am. J. Med. 57:927-939.

25. Reimer, R. R., R. Hoover, J. F. Fraumeni, Jr., and R. C. Young. 1977. Acute leukemia after alkylating-agent therapy of ovarian cancer. N. Engl. J. Med. 297:177-181.

25a. Picken, M. M., G. Gallo, J. Buxbaum, and B. Frangione. 1986. Characterization of renal amyloid derived from the variable region of the lambda light chain subgroup II. Am. J. Pathol. 124:82-87.

26. Sox, H. C., Jr., and L. Hood. 1970. Attachment of carbohydrate to the variable region of myeloma immunoglobulin light chains. Proc. Natl. Acad. Sci. USA. 66:975-982.

27. Spiegelberg, H., C. A. Abel, B. G. Fishkin, and H. M. Grey. 1970. Localization of the carbohydrate within the variable region of light and heavy chain of human $\gamma \mathrm{G}$ myeloma proteins. Biochemistry. 9:42174223.

28. Argon, Y., O. R. Burrone, and C. Milstein. 1983. Molecular characterization of a nonsecreting myeloma mutant. Eur. J. Immunol. 13:301-305.

29. Kemp, D. J., A. W. Harris, S. Cory, and J. M. Adams. 1980. Expression of the immunoglobulin $\mathrm{C}$ gene in mouse $\mathrm{T}$ and $\mathrm{B}$ lymphoid and myeloid cell lines. Proc. Natl. Acad. Sci. USA. 77:2876-2880.

30. Bonvet, J. P., T. Pillot, and P. Liacopoulous. 1983. Human myeloma light chains with increased molecular weight: high frequency among $\lambda$ chains. Mol. Immunol. 20:397-407.

31. Williams, R. C., Jr., S. B. Pinnell, and G. T. Bratt. 1966. Low molecular weight components related to Bence-Jones proteins. J. Lab. Clin. Med. 68:81-89.

32. Solomon, A., J. Killander, H. M. Grey, and H. G. Kunkel. 1966. Low molecular weight proteins related to Bence-Jones proteins in multiple myeloma. Science (Wash. DC). 151:1237-1239.

33. Preud'Homme, J. P., L. Morel-Maroger, J. C. Brouet, M. Cerf, F. Mignoon, P. Guglielmi, and M. Seligmann. 1980. Synthesis of abnormal immunoglobulins in lymphoplasmacytic disorders with visceral light chain deposition. Am. J. Med. 69:703-710.

34. Gallo, G. R., H. D. Feiner, L. A. Katz, G. M. Feldman, E. B. Correa, J. V. Chuba, and J. N. Buxbaum. 1980. Nodular glomerulopathy associated with nonamyloidotic kappa-light chain deposits and excess immunoglobulin light chain synthesis. Am. J. Pathol. 99:621-644.

35. Virella, G., and I. M. Coelho. 1974. Unexpected mobility of human lambda chains in sodium dodecyl sulphate-polyacrylamide gel electrophoresis. Immunochemistry. 11:157. 